\title{
Has Robert Parker lost his hegemony as a prescriptor in the wine World? A preliminar inquiry through Twitter
}

\author{
Compés-López, Raúl ${ }^{\text {a b}}$; Font-Julian, Cristina I. $^{\text {b }}$ and Orduna-Malea, Enrique ${ }^{\text {b }}$ \\ ${ }^{a}$ Departmento de Economía y Ciencias Sociales; ${ }^{b}$ Universitat Politècnica de València, Spain
}

\begin{abstract}
The aim of this work is to determine to what extent Robert Parker has lost his influence as a prescriber in the world of wine through a webometric analysis based on a comparative analysis of Parker's web influence and that of a competitor who represents an anthitetical vision of the world of wine (Alice Feiring). To do this, we carried out a comparative analysis for Parker's (@wine_advocate) and Alice_Feiring's (@alicefeiring) official Twitter accounts, including a broad set of metrics (productivity, age, Social Activity, number of followees, etc.), paying special attention to specific followers' features (age, gender, location, and bios text). The results show that Parker's twitter profile exhibits an overall higher impact, which denotes not only a different online strategy but also a high level of engagement and popularity. The low level of shared followers by Parker and Feiring (1,898 users) offer prima facie evidence of an online gap between these followers, which can indicate the existence of a divided group of supporters corresponding with the visions that Parker and Feiring represent. Finally, special features are notice for Feiring in gender (more women followers), language (more English-speaking followers) and country (more followers from the United States).
\end{abstract}

Keywords: Robert Parker; Wine industry; Wine prescriptor; Webmetrics; Web data analysis; Twitter data. 


\section{Introduction}

The globalization of the wine world and the increase in the number of wineries and brands in recent decades has caused a great demand for information from consumers. The value of a product depends on the valuation of its different types of attributes, but not all of these attributes can be attained by the consumer for the same price (Compés, 2002). In the case of wine, the search attributes are the least expensive to know, since they consist of information that the consumer can find out directly before buying. The trusted attributes are the most complex, but the existence of Denominations of Origin and other third-party certifying entities allows them to be converted into search attributes. At that point, the attributes posing the greatest problems are the those of experience -taste, flavour-, which can be known directly, but only after having acquired and tested the product, which means that there is a risk, especially for wines with a higher price. A personal testing or the advice of a friend would eliminate or reduce this risk, but the consumer is not always able to taste the wines before buying them or have a trusted friend next to him at the time of purchase.

To avoid the market failures associated with this type of informational asymmetry, a powerful industry of information and specialized valuation has been created in the main wine markets of the world. This industry is formed by journalists, guides, apps, magazines and competitions. All of them, through their comments, ratings and distinctions, aim to guide the decisions of the consumers. When they are very influential, the wines come to bear their marks/labels (Orth \& Krška, 2001), which convert the attributes of experience into attributes of search; wineries even try to elaborate wines that satisfy their tastes in order to obtain the best valuations and scores. In these cases, the administrators of the ratings become prescribers or gurus (Ali et al., 2008; Huang et al., 2009), and influence the choice of many consumers (Chocarro \& Cortiñas, 2013, Hamerson, 2010).

Although there are several famous and respected critics including Jancis Robinson, Michael Broadbent, Steven Tanzer, Jean-Marc Quarin or James Suckling, the greatest prescriber in the world of wine is Robert Parker. He has been considered not only the most influential critic (Bowman, 2009) but even the Wine Emperor (McCoy, 2014). His influence in the world wine industry, exercised through his publication Robert Parker's Wine Advocate, has been extensive. It has influenced tasting notes (James, 2018), wine rhetoric (Hommerberg, 2011) and wine valuation criteria (Cardebat \& Livat, 2016) including the famous "Parker points" (Shapin, 2005). His valuations have created a trend in wine production parkerization- based on his tastes in favor for bold, fruity, and concentrated wines, especially in Bordeaux (Parker, 2003; Hay, 2010). Parker's vision and tastes have influence the wine industry, provoking a homogenization that goes against terroir and differentiation. Nonetheless, Parker is one of the reasons behind the great growth of the wine demand in the US (becoming the first world wine market to overcome France). The hegemony of Robert Parker and the threat of the consequent homogenization and industrialization of the wine 
world (Torrès, 2016) have provoked an opposite reaction, with one of its main critics being Alice Feiring (2008).

The objective of this paper is to determine to what extent Robert Parker has lost his influence as a prescriber in the world of wine. To do this, we investigated whether his Journal and other ways to disseminate his comments and points are being less followed, and if his critics have been found to be increasing their influence. As a preliminary attempt to carry out this goal, a webometrics approach (Thelwall, 2009; Orduna-Malea and Aguillo, 2015), in its business side (Orduna-Malea \& Alonso-Alonso, 2017), is applied. In this specific case, Twitter data (Zimmer \& Proferes, 2014) will be used to ascertain whether Parker's vision of wine is losing influence against his main critic Alice Feiring.

\section{Method}

In order to proceed with a comparison between the wine's world visions of Robert M. Parker Jr. (hereinafter, Parker) and Alice Feiring (hereinafter, Feiring), data from Twitter was gathered. The official Twitter accounts of Parker (@wine_advocate) and Feiring (@alicefeiring) were considered. Followerwonk (https://moz.com/followerwonk) data source was then used to extract the following metrics from each profile: Age (number of years since the creation of the Twitter account), Followers, Friends, Likes, and Social Authority (score from 0 to 100 reflecting the importance of each account). Additionally, a deep analysis of both Parker and Feiring's followers (17,128 and 14,927 followers respectively) was carried out, obtaining information about followers' language, precedence, and gender. Moreover, keywords included in the followers' Bios field were extracted and analysed by a text analyser (https://www.online-utility.org/text/analyzer.jsp) in order to find out the main common terms used by followers.

Additionally, queries in Google Trends (https://trends.google.com/trends) were performed to check the relevance of Parker's vision over time. The queries "The Wine Advocate" and "Robert M. Parker Jr." on the one hand, and "The Feiring Line" and "Alice Feiring") on the other were queried (location: Worldwide; source: Web search; timespan: since 2004).

All data gathering and queries were performed during the first week of March 2018.

\section{Results}

\subsection{Web search trends}

The relative search interest for "The Wine Advocate" has declined notably since 2004 (Figure 1). Furthermore, the results obtained for "Robert M. Parker Jr." reinforce a fall of 
interest in the "Parker's wine vision". However, this drop cannot be related with a rise of a "Feiring's wine vision". The query "Alice Feiring" cannot be included in Figure 1 since the relative search interest (if compared with Parker results) is below " 1 " for $51.5 \%$ (88) of the months measured, and just " 0 " for $25 \%$ (43) of the months. Supplementary queries such as "The Feiring line" provide few results as well.

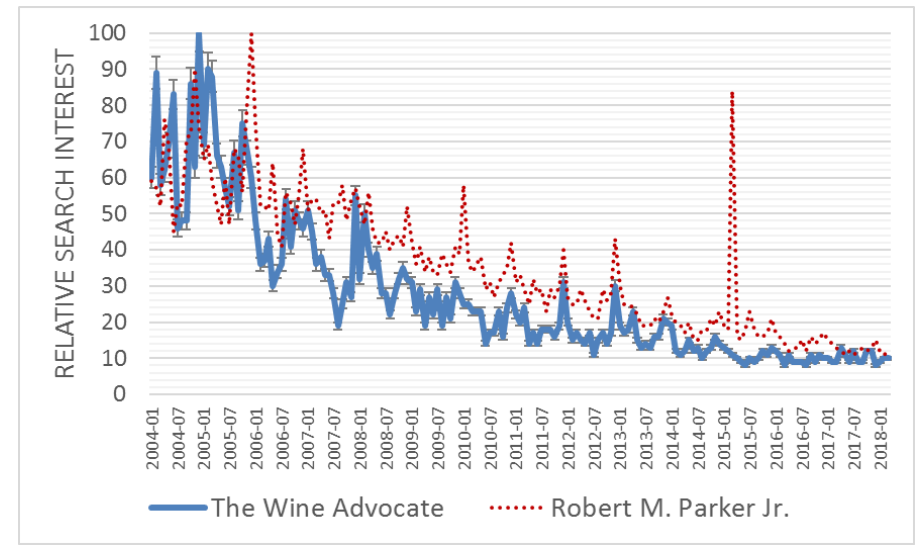

Figure 1. Search trends comparison over time.

Source: Google Trends (Worldwide; in the entire web; since 2004)

Regarding the geographical location of users, the query "Robert M Parker Jr." exhibits a greater breakthrough worldwide. Considering apart the special interest in English-speaking countries (United States, United Kingdom, Australia, South Africa), it's noteworthy the interest in Spain, France, Germany, and Latin America (Argentina and Chile). On the opposite, the query "Alice Feiring" exhibits a more restricted interest, focused mainly in the United States, France, and Spain.

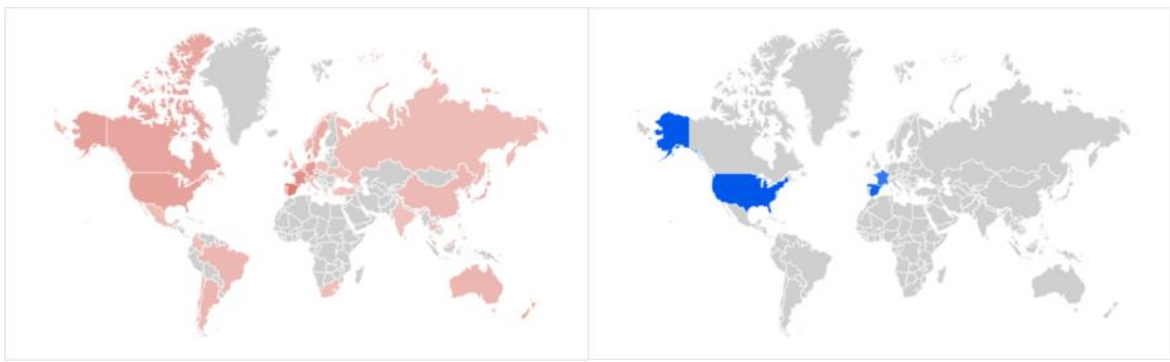

Figure 2. Geolocalized searches for "Robert M Parker Jr" (left) and “Alice Feiring” (right). Source: Google Trends

\subsection{Twitter profiles comparison}

Parker obtains a higher number of followers $(17,128)$, likes $(4.523)$ and social authority (54) than Feiring (Table 1). This is quite remarkable since Parker's Twitter profile follows 
less friends (37), is younger (under 5 years) and is less productive $(3,868$ tweets), what does not prevent him from obtaining a greater percentage of ReTweets (32.5\% against $21.5 \%$ ). Conversely, Feiring's account is very productive (13,311 tweets published) and follows more users $(1,203)$. Otherwise, the number of followers shared by the two accounts is low (1,898 followers). That is, only $11 \%$ of all Parker's followers follow Feiring.

Table 1. Principal metrics for Parker and Feiring's Twitter profiles.

\begin{tabular}{ccc}
\hline Metrics & Parker & Feiring \\
\hline Social Authority & 54 & 46 \\
Followers & 17,128 & 14,927 \\
Age & 4.61 years & 9.33 years \\
Tweets & 3,869 & 13,311 \\
Likes & 4,523 & 3,105 \\
Friends & 37 & 1,203 \\
\multicolumn{2}{r}{ Source: Followerwonk }
\end{tabular}

The average social authority of Feiring's followers is slightly higher (17.23) than Parker's (16.93). The distribution of followers according to their social authority is uneven (Figure 3). Only 5.7\% (968) of Parker's followers obtain a social authority score at least of 50. In a similar way, only 5.3\% (790) of Feiring's followers achieve this score.
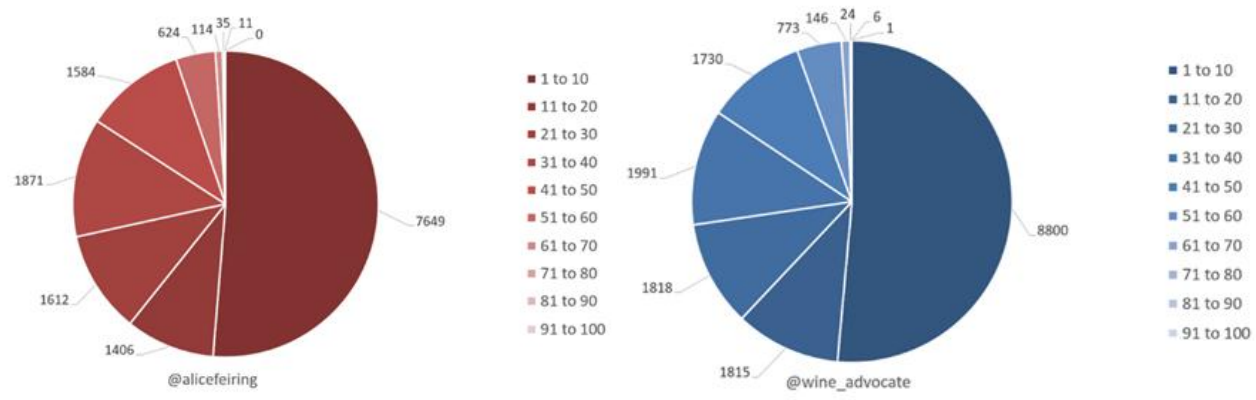

Figure 3. Distribution of followers' social authority.

Source: Followerwonk.

\section{Gender}

Despite the huge percentage of users to whom it was not possible to determine the gender (50.9\% in the case of Parker, and $54.6 \%$ for Feiring), we observe a greater percentage of male followers in both profiles (Parker: 36.3\%; Feiring: 27.2\%). However, the percentage of female followers is greater in the case of Feiring (18.1\%) than for Parker $(12.7 \%)$. 


\section{Language}

As regards the language used by followers, English predominates both for Parker $(61.3 \%$ of followers) and for Feiring (83.9\%), followed by Spanish (18.5\% and $4.5 \%$ respectively), French $(6.4 \%$ and $4.4 \%)$, and Italy $(5.6 \%$ and $4 \%)$.

\section{Bios keywords}

The top 5 keywords included in the bios field of the followers are displayed in Table 2. Single words without enough meaning themselves (world, wine, food...), void terms (the, and, to...) and senseless composed terms (of the, the best, the wine...) were excluded. Likewise, variants were merged (eg. 'food and wine' and 'food \& wine'). Although the most frequent terms are quite similar in both Twitter profiles, the higher frequency of Winery and Sommelier for Feiring, despite having a less number of followers is notewhorty.

Table 2. Keywords included in Bios of Twitter followers.

\begin{tabular}{cccc}
\hline \multicolumn{2}{c}{ PARKER } & \multicolumn{2}{c}{ FEIRING } \\
Keyword & N & Keyword & N \\
\hline Winery & 351 & Winery & 472 \\
Sommelier & 345 & Sommelier & 452 \\
Food wine & 231 & Food wine & 332 \\
Fine wine & 210 & Wine food & 282 \\
Wine lover & 186 & Wine lover & 157 \\
\hline \multicolumn{3}{c}{ Source: Followerwonk. }
\end{tabular}

\section{Geographical location}

Two main zones in Europe (Paris and London) with a similar concentration of followers for both (Figure 4; top) are observed. Otherwise, a greater concentration of Parker's followers is observed in Spain. In the United States (Figure 4; bottom), the three main centres of interest correspond with the areas of New York, San Francisco and Los Angeles, where the concentration of followers is greater for Feiring. However, data should be taken cautiously since maps are plotted considering up to 5,000 Twitter users for each account $(29.2 \%$ of all Parker's followers, and $33.5 \%$ of Feiring's). 

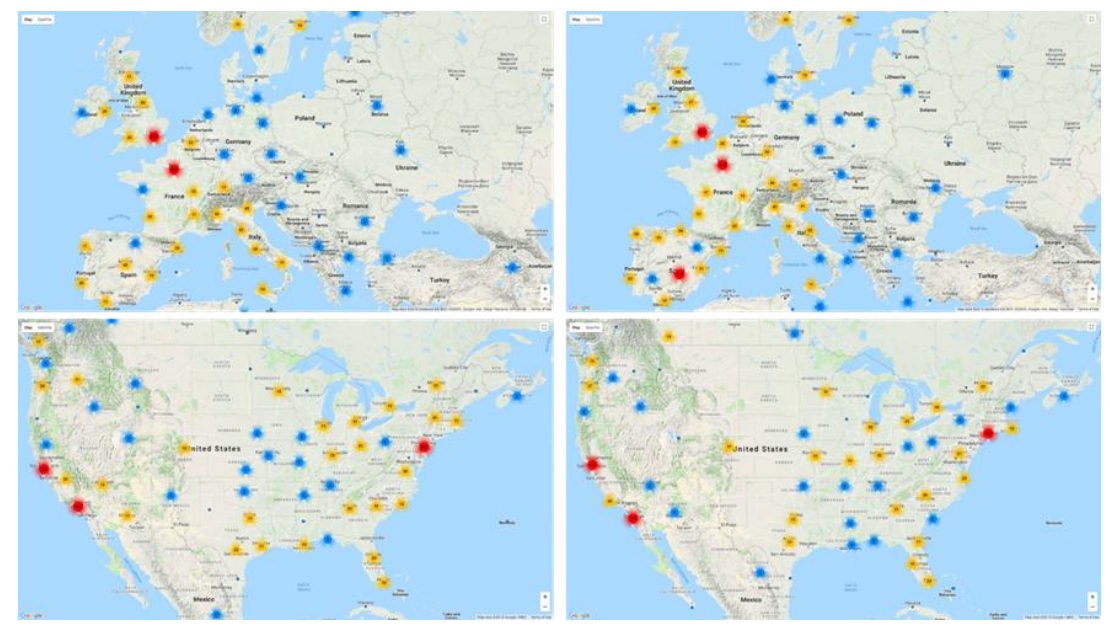

Figure 4. Geolocation of Feiring's followers (left) and Parker's (right) in Europe (up) and United States (below).

Raw data has been manually explored to contrast this approximation. In the case of Parker, geographical data is available only for the $67.4 \%$ (11,543) of followers, whereas for Feiring is $79.4 \%$ (11,849 followers). Even so, the percentage of useful data is still lower since users tend to full the geographical data field with invented terms ("Here", "somewhere", "At lunch"), imprecise locations or simply spam (i.e: "Contact us for promotions"). After clustering data at a country-level, Parker's followers come basically from 5 countries: USA $(3,546)$, Spain (1,536), UK (1,092), France (832) and Italy (684). These same countries are the main places from which Feiring's followers come from, although with differences in their ranking positions: US (5,958), UK (886), France (574), Italy (496), and Spain (410).

\section{Discussion and conclusions}

The results obtained find a decline in search interest for terms related both to "Robert Parker" and "The Wine Advocate". This may reflect a decline of 'Parker's vision of wine'. It can also be underlined that The Wine Advocate search goes down, during a long time, more than Robert Parker's. A feasible explanation may be due to the fact that 'Robert Parker' becomes a trademark most important than his mean. In any case, it is obvious that although Robert Parker has lost influence, he has created a methodology in the way of measuring and valuing a wine - the famous Parker points - that has been imitated by other critics and has educated thousands of consumers, and this is already part of his legacy.

However, this fall could be due also to the fact that users access alternative sources instead of personal websites. Precisely, the Twitter analysis does not find a Parker's alternative vision through Feiring. Parker's profile exhibits an overall higher impact, which denotes not only a different profile strategy but also a high level of engagement and popularity. The 
low level of shared followers could be indicative of different (almost antagonic) positions in the world of wine. However, a deeper analysis of followers' activities and preferences is still necessary. Yet, special features are notice for Feiring in gender (more women followers), language (stronger influence of English) and country (strong influence in the United States). Likewise, it seems that Feiring's followers are more related to wine professionals than Parker's, more pure consumers.

However, this results should be taken cautiously since the tools used may introduce a coverage bias. Other platforms (Facebook, Instagram, etc.) and techniques (opinion mining, link analysis, etc.) must complement this work equally. The identification of two positions (Parker and Anti-Parker) needs of more quantitative and qualitative methods as well. In this case, only Alice Feiring has been studied as a banner of the "anti-Parker" wine vision, it would be also useful to compare Robert Parker's influence with the other great wine critics, some of them editing also their own journals. Finally, it would be necessary to analyse Parker's tasting notes and the terms used to categorize the highest scoring wines, and compare them with the competition and its critics in order to get a deeper understanding of the movements - in terms of wine prescriptors, trends and fashions - in the market of wine.

\section{References}

Ali, H. H., Lecocq, S., \& Visser, M. (2008). The impact of gurus: Parker grades and en primeur wine prices. The Economic Journal, 118(529), 158-173.

Bowman, S. (2009). Uprooting Robert Parker. Gastronomica: The Journal of Critical Food Studies, 9(1), 98-101.

Cardebat, J. M., \& Livat, F. (2016). Wine experts' rating: a matter of taste?. International Journal of Wine Business Research, 28(1), 43-58.

Chocarro, R., \& Cortiñas, M. (2013). The impact of expert opinion in consumer perception of wines. International Journal of Wine Business Research, 25(3), 227-248.

Compés, R. (2002). Atributos de confianza, normas y certificación: comparación de estándares para hortalizas. Economía agraria y recursos naturales, 2(1), 115-130.

Feiring, A. (2008). The Battle for Wine and Love: Or How I Saved the World from Parkerization. Orlando (FL): Houghton Mifflin Harcourt.

Hapin, S. (2005). Hedonistic fruit bombs. London Review of Books, 27(3), 30-32.

Hay, C. (2010). The political economy of price and status formation in the Bordeaux en primeur market: the role of wine critics as rating agencies. Socio-economic review, 8(4), 685-707.

Hommerberg, C. (2011). Persuasiveness in the discourse of wine: The rhetoric of Robert Parker (Doctoral dissertation). Växjö (Sweden): Linnaeus University Press.

Huang, P., Lurie, N. H., \& Mitra, S. (2009). Searching for experience on the web: an empirical examination of consumer behavior for search and experience goods. Journal of marketing, 73(2), 55-69. 
Jamerson, H. M. (2010). Wine Tastes: The Production of Culture among Service Workers and Consumers in Napa Valley Wineries (doctoral dissertation). Atlanta: Emory University.

James, A. (2018). How Robert Parker's 90+ and Ann Noble's Aroma Wheel Changed the Discourse of Wine Tasting Notes. ILCEA. Revue de l'Institut des langues et cultures d'Europe, Amérique, Afrique, Asie et Australie, (31), Online.

McCoy, E. (2014). The Emperor of Wine: The Rise of Robert M. Parker, Jr., and the Reign of American Taste. New York: Harper Collins.

Orth, U. R., \& Krška, P. (2001). Quality signals in wine marketing: the role of exhibition awards. The International Food and Agribusiness Management Review, 4(4), 385-397.

Parker, R. M., \& Rovani, P. A. (2002). Parker's wine buyer's guide. New York: Simon and Schuster.

Parker, R. M. (2003). Bordeaux: a consumer's guide to the world's finest wines. New York: Simon and Schuster.

Thelwall, M. (2009). Introduction to webometrics: Quantitative web research for the social sciences. San Rafael (CA): Morgan \& Claypool.

Torrès, O. (2006). Introduction: The McDonaldization of Wine. London: Palgrave Macmillan.

Orduña-Malea, E., \& Aguillo, I. F. (2015). Cibermetría. Midiendo el espacio red. Barcelona: UOC Publishing.

Orduña-Malea, E., \& Alonso-Arroyo, A. (2017). Cybermetric Techniques to Evaluate Organizations Using Web-based Data. Oxford: Chandos Publishing.

Zimmer, M. \& Proferes, N. J. (2014). A topology of Twitter research: disciplines, methods, and ethics“. Aslib Journal of Information Management, 66(3), 250-261. 